International Journal of Instruction e-ISSN: 1308-1470 • www.e-iji.net

Article submission code: 20201227193257

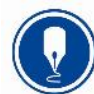

October $2021 \bullet$ Vol.14, No.4

p-ISSN: 1694-609X

pp. 933-944

Received: 27/12/2020

Revision: 07/05/2021
Accepted: 01/06/2021

OnlineFirst: 10/09/2021

\title{
Dimensionality of the Rosenberg Self-Esteem Scale among Greek Primary School Students
}

\section{Angeliki Syropoulou}

$\mathrm{PhD}$ candidate, corresponding author, Department of Physical Education \& Sport Science, Democritus University of Thrace, Greece, agsyropo@phyed.duth.gr

Nikolaos Vernadakis

Asst. Prof., Department of Physical Education \& Sport Science, Democritus University of Thrace, Greece, nvernada@phyed.duth.gr

\section{Marina Papastergiou}

Asst. Prof., Department of Physical Education \& Sport Science, University of Thessaly, Greece,mpapas@pe.uth.gr

Thomas Kourtessis

Prof., Department of Physical Education \& Sport Science, Democritus University of Thrace, Greece, tkourtes@phyed.duth.gr

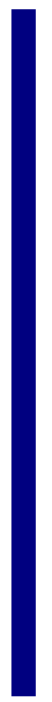

The aim of the current study was to validate the self-report version of the Rosenberg Self-Esteem Scale (RSES; Rosenberg, 1965) structure in a sample of Greek primary school students. The study was based on the original one-factor model suggested by the scale's author, as well as on the two-factor correlated model of positive and negative items. Participants were 652 primary school students $(\mathrm{N}=652, \mathrm{M}=10.02, \mathrm{SD}=1.160)$. The psychometric properties of the RSES were assessed by conducting a Confirmatory Factor Analysis (CFA). Both average variance extracted and composite reliability were used to test the internal consistency and convergent validity. The correlated two-factor model provided a better fit to the data than the one-factor model, according to the CFA. This conclusion is based on the analysis results, which comprised as providing good fit if non-significant $\chi 2$ values, $\chi 2 / \mathrm{df}<1.5$, the Tucker Lewis index (TLI) and the comparative fit index $(\mathrm{CFI}) \geq 0.95$ (acceptable at $>0.90)$, as well as the root mean square error of approximation (RMSEA) $<0.06$ (Hu \& Bentler, 1999). The main contribution of this study was the adaptation and evaluation of the RSES for use of Greek students and the determination of its factor structure. Teachers and researchers could also use this interpreted scale to determine the level of selfesteem in primary school children and form strategies to increase their self-esteem.

Keywords: self-esteem, children, psychometric, Rosenberg self-esteem scale, confirmatory factor analysis

Citation: Syropoulou, A., Vernadakis, N., Papastergiou, M., \& Kourtessis, T. (2021). Dimensionality of the rosenberg self-esteem scale among Greek primary school students. International Journal of Instruction, 14(4), 933-944. https://doi.org/10.29333/iji.2021.14453a 


\section{INTRODUCTION}

Over the years, several definitions of self-esteem have been formulated. Rosenberg (1985, as cited in Kobal \& Musek, 2001) has defined self-esteem as the positive or negative attitude of a person towards oneself, which is closely associated with the feeling of life satisfaction. Global self-esteem can be described as a general appreciation of being a valuable person (Baumeister, 1993; Branden, 1994; Rosenberg, 1979) and it forms an attractive subject for comprehensive research across numerous research fields, such as psychopathology (e.g. Joiner, 1995; Ralph \& Mineka, 1998) and health psychology (e.g. Penninx et al., 1998; Silver et al., 1995).

After having compared groups of people with high and low self-esteem, Schacter, Gilbert and Wegner (2012) report that people with high self-esteem tend to live happier and healthier lives and to better cope with stress, compared to those with low selfesteem, who are more likely to interpret controversial feedback from a third party as a rejection. What is more, low self-esteem has been associated with depression, anorexia nervosa and other eating disorders, adjustment problems and suicide (Jacobs et al., 2003; Schacter et al., 2012). On the contrary, high self-esteem has been positively associated with specialty satisfaction level (Alsalkhi, 2018). As far as children are concerned, it becomes obvious that development of their self-esteem, which can be positively affected by physical activity (Batsiou, Bournoudi, Antoniou, \& Tokmakidis, 2020), is crucial for their happiness in life (Cole \& Cole, 2001).

The most popular mean/tool (Byrne, 1996) utilised for measuring the global self-esteem is the self-report version of the Rosenberg Self-Esteem Scale (RSES; Rosenberg, 1965). RSES directly reflects the global self-esteem of an individual through a set of ten items. The questionnaire is addressed to individuals over 11 years old and has a reliability index (Cronbach's alpha) of 0.87. The RSES is comprised of five positively worded and five negatively worded items. Thanks to its simple structure and ease of access, the scale has been translated and adjusted onto several languages, including Greek (Galanou et al., 2014).

In spite of RSES demonstrating an evident superficial factor structure with both regular and reverse-keyed elements (Corwyn, 2000; Whiteside-Mansell \& Corwyn, 2003), some preliminary studies have noticed that underlying sub factors are present within the RSES (DiStefano \& Motl, 2009). DiStefano and Motl (2009) claimed that the two-factor arrangement of the RSES encompasses a positive and a negative self-esteem factor. The sample of their study included 678 university students, 316 males and 362 females $(\mathrm{M}=22.4$ years; $\mathrm{SD} \pm 7.2$ years; age range $16-75$ years $)$. Miller, Topping and Thurston (2010) used the above two-factor structure of the RSES, in their study with a sample of primary school children. The aim of their research was to assess the changes in selfesteem of children participating in a randomized trial of Paired Reading over a 15-week treatment period and to examine the relative contribution of self-worth and selfcompetence to any improvement in self-esteem levels.

As a consequence, there is a continuing debate in literature regarding self-esteem and specifically whether these latter conclusions either imply the presence of two 
significantly different latent factors or derive from an undesirable method effect that is caused from the positive and negative wording of items (Tomás et al., 2016). However, it must be noted that the tendency for positive and negative terminology to be classified into two factors does not essentially infer a fundamental distinction between positive and negative self-esteem (Greenberger et al., 2003).

Certain researchers have claimed that the RSES seems to correspond to a unidimensional construct of global self-esteem (Corwyn, 2000). However, it is likely to be influenced by method effects predominantly related to positively and negatively worded items (Corwyn, 2000). Other researchers (Kaufman et al., 1991) claimed that the scale may depict a two-dimensional structure, as these two factors represent the positive and negative images of the self.

Regardless of the dispute about the number of factors, not many studies have been focused on the investigation of this issue in the Greek language (Michaelides et al., 2016). On top of that, in spite of the fact that the RSES has been broadly applied in certain age groups of the Greek population, no verification has been done over Greek primary school students. Since this scale is particularly inconsistent across age groups, further research must be carried out in primary school students. Hence, the current study is predominantly aiming in the confirmation of the RSES structure in a sample consisting of Greek primary school students. The study shall be based on the original one-factor model proposed by the scale's author, as well as on the two-factor correlated model of positive and negative items and shall adapt the scale for this sample.

\section{METHOD}

The experimental procedure complied with the Helsinki declaration of 1975 and was approved by the Ethics Committee of the University of Thessaly (Greece).

\section{Participants and materials}

In total 652 children took part in the research. $348(53.4 \%)$ of them were male while the remaining $304(46.6 \%)$ were female. These children attended public primary schools across different parts of Greece (i.e. Rhodes, Kos, Athens, Katerini, Florina and Thessaloniki) and have an age of 10.02 years on average $(\mathrm{SD}=1.160)$. As part of the research preparatory stage, the study's purpose, nature, design, and duration were thoroughly described and stated to the principal and teachers of each school. The sample was convenient, while all participants populated a self-report survey without quoting their own personal details. Students' participation in this research was voluntary and was granted upon obtaining written permission from their parents. Finally, it must be highlighted that the experimental procedure complied with the Helsinki declaration of 1975 and was approved by the Ethics Committee of the University of Thessaly.

\section{Instrument}

Rosenberg Self-esteem Scale (RSES) (Rosenberg, 1965).

The RSES comprises 10 Likert-type scale items designed to assess positive and negative evaluations of a person. The total score ranges from 10 to 40 , as a result of the participants responds that describe the level of agreement ranging from 1 (strongly disagree) to 4 (strongly agree). Despite the fact that RSES has been translated to the 
Greek language (Galanou et al., 2014), the translated scale was susceptible to limitations, as there was no clear statement that translation was performed by a professional translator fluent both in Greek and English (or a native speaker). As a consequence, RSES was re-translated to Greek language for the subsequent assessment of its reliability, validity, and equivalence.

\section{RSES'translation.}

Concerning the procedure of the RSES translation, the repeated "back and forth" methodology was selected as the most suitable approach. Initially, the Greek version of the scale was handled by a professional translator fluent in Greek and English who translated it to English, by proposing a number of alternative versions where applicable. Thereafter, a committee consisting of four members of the research project group at the time produced a first draft version of the scale, by considering the initial recommendations. This version was then sent to a second professional translator (blinded to the original items) that was both an English native speaker and fluent in Greek, so that a back-translation to English could be performed efficiently. Finally, comparison between the back-translated version and the original English version was undertaken to check consistency across each version's meaning, any discrepancies occurs were scrutinised by both translators and resolved.

An important task of the committee members involved the assessment of the translation quality of each item between the original English version and the Greek version of the RSES on a 4-point Likert scale varying from $1=$ non-equivalent to $4=$ very equivalent. The level that the meaning of each item has been maintained to in the target culture, upon translation from the original, is defined as semantic equivalence. Thereafter, an equivalence rate calculation was undertaken, to determine the proportion of the total items that were rated as greater than 2 by the experts. Any item deemed non-equivalent (i.e., with a score less than 3 ) was adjusted.

Similarly, the content equivalence of the RSES Greek version using a 4-point Likert scale ranging from $1=$ not relevant to $4=$ very relevant was assessed by the committee members. Content equivalence demands that each item's content be applicable to each culture, by acknowledging that some constructions cannot be used in instruments that may be found in various cultural contexts. The content validity index is specified as the percentage of total RSES items that received a rating of 3 or 4 from committee members. Should this proportion be greater than $80 \%$, the new instrument is deemed suitable (Beck \& Gable, 2001). The number of items listed in the Greek version of the RSES remained the same.

\section{Procedure}

The questionnaire was administered to the students in their class. The researcher contacted the teachers and the principals of the schools and sent them the RSES. The teachers distributed the questionnaires only to students who would participate in the research. The questionnaires were gathered from the teachers and stored in a box that was finally sent back to the researcher. On the average, the completion time for the scale was 4 minutes approximately. 


\section{RSES' models}

The first model is the one-factor type without error covariance, based on the assumption that item responses can be explained by a common latent trait, self-esteem. In addition, the second model is the two factor orthogonal type with two independent correlated latent traits, where all negatively-worded items are loaded on one factor (labelled neg), and all positively-worded items are loaded on another factor (labelled pos). The two models are represented at the Figure 1.

MODEL 1

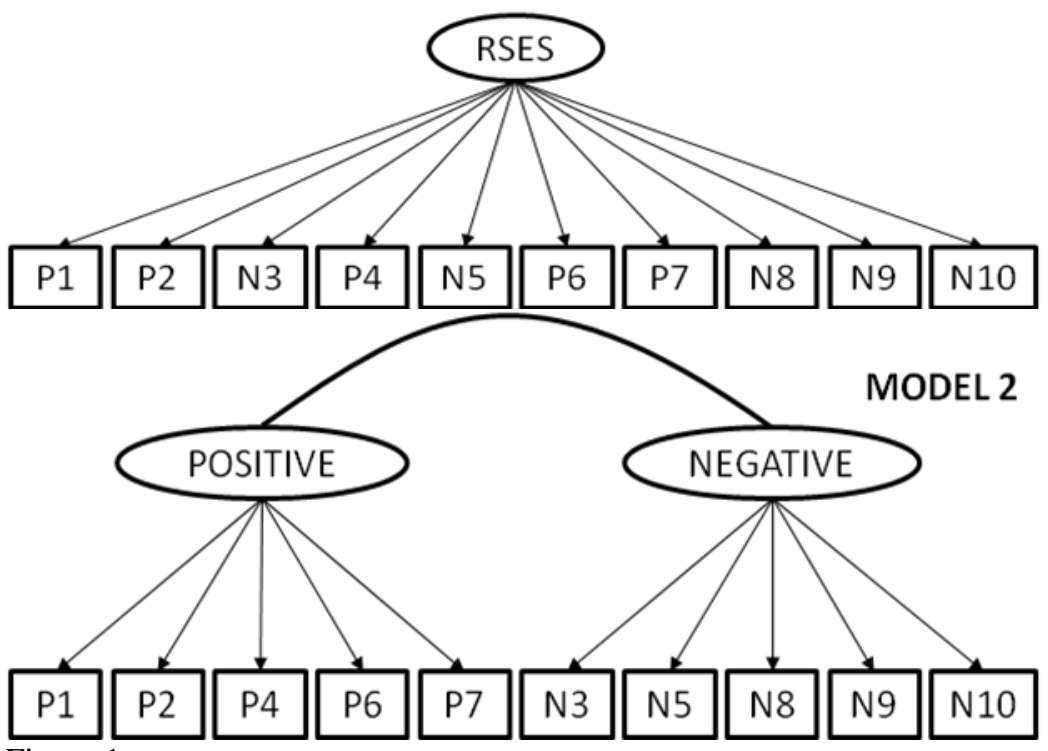

Figure 1

The two RSES models

\section{Data analysis}

Descriptive and correlational analyses were computed for each RSES item and for the overall score. For all items, the measures of skewness and kurtosis were examined prior to conducting a factor analysis, with a view to determining whether the items were normally distributed. Several authors (Baron, 2018; Tabachnick \& Fidell, 2019) have suggested that items with levels of skewness $>2.5$ and levels of kurtosis $>3.0$ should be eliminated. As it concerns the correlational analyses, items that did not exhibit reasonable correlation (of $\geq 0.30$ ) with at least one other item were eliminated prior to the factor analysis (Baron, 2018).

The model comparison procedures were conducted within a CFA framework. In order to determine the fit of the specified model, series of model fit indices were conducted. The overall fit of the data model was also examined using Bentler's CFI, the TLI, the RMSEA, Chi-Square $(\chi 2)$, Chi-Square/degrees of freedom ratio $\left(\chi^{2 / d}\right.$.f. ratio) and SRMR. 
The $\chi 2$ statistic indicates the difference between the observed and the expected matrices of covariance. Tabachnick and Fidell (2019) stated that values closer to zero indicate smaller differences between expected and observed covariance matrices. Thus, a nonsignificant $\chi^{2}$ is desired in order to support the fit model. CFI analyzes the model fit by examining the discrepancy between the data and the hypothesized model, while adjusting for the issues of sample size inherent in the $\chi 2$ statistic for model fit ( $\mathrm{Hu} \&$ Bentler, 1999). CFI values range from 0 to 1 , with larger values indicating a better fit. According to $\mathrm{Hu}$ and Bentler (1999), CFI values above 0.90 suggest an acceptable fit and values above 0.95 a close fit. TLI is an incremental index that measures fit while adding a penalty for complexity (Bollen \& Long, 1993). The TLI values ranges from 0 to 1 , with values closer to 1 indicating a good fitting model. Research has shown that a TLI value above 0.90 is acceptable; however, values of .95 and higher are more desirable (Hu \& Bentler, 1999). RMSEA avoids issues of sample size by analyzing the discrepancy between the hypothesized model, with optimally chosen parameter estimates, and the population covariance matrix (Hooper, Coughlan \& Mullen, 2008). SRMR is the square root of the discrepancy between the sample covariance matrix and the model covariance matrix (Hooper et al., 2008). Hu and Bentler (1999) state that a value of 0.08 or less of the above fit indices (RMSEA, SRMR) indicative of an acceptable model.

Furthermore, three information criteria related to parsimony were also included as an additional measure for comparing the fit of alternative models: a) Akaike Information Criterion (AIC), b) the Bayesian information criterion (BIC), which penalizes for model complexity more profoundly, and c) the Consistent AIC (CAIC), which takes sample size into account. Lower AIC, BIC and CAIC values represent a better fit of the hypothesized model.

The internal consistency of the factors and the convergent validity were measured by the average variance extracted (AVE) and the composite reliability (CR), respectively. Values above 0.50 are recommended for the AVE (Fornell \& Larcker, 1981), and the minimum CR value considered to be adequate is 0.70 (Nunnally, 1978). In case of AVE is less than 0.5 but $\mathrm{CR}$ is higher than 0.6 , the convergent validity of the construct is still adequate (Fornell \& Larcker, 1981).

To obtain the descriptive statistics, internal consistency coefficients and correlation matrices, the IBM Statistical Package for the Social Sciences (SPSS) software, version 22 for Windows (SPSS Inc., Chicago, IL, USA) was used. The CFAs were conduct using the IBM Amos statistical package for analysis of covariance structures (version 22).

\section{FINDINGS}

In what follows, the results of the semantic and the content equivalence analyses are presented first, followed by the descriptive and correlational analyses results. Subsequently, the results of the confirmatory factor analyses are presented, followed by the results of the validity and reliability analyses. 


\section{Semantic and content equivalence}

For the purpose of obtain semantic and content equivalence, each item must remain idiomatically and conceptually the same after translation, while at the same time being culturally relevant. The content validity index (CVI) of content relevance and semantic equivalence for were calculated. The semantic equivalence rating was 96 per cent, indicating that item of the Greek version of the RSES remained idiomatically and conceptually the same as in the English version. CVI was 94\%, suggesting that the content of the Greek edition of the RSES was valid.

\section{Descriptive and correlational analysis}

Descriptive statistics and univariate normality measures were performed for each item of the RSES. These included range, means, standard deviations, and measures of skewness and kurtosis for the 10 items of the RSES as well as for its overall score, namely GSE (Table 1).

Table 1

Descriptive statistics and univariate normality measures of RSES items

\begin{tabular}{llllll}
\hline Items & Range & M & SD & Skewness & Kurtosis \\
\hline P1 & $1-4$ & 3.40 & 0.68 & -1.14 & 1.65 \\
\hline P2 & $1-4$ & 3.36 & 0.67 & -0.82 & 0.56 \\
\hline N3 & $1-4$ & 2.62 & 1.02 & -0.12 & -1.10 \\
\hline P4 & $1-4$ & 3.34 & 0.75 & -1.00 & 0.67 \\
\hline N5 & $1-4$ & 2.68 & 1.05 & -0.22 & -1.16 \\
\hline P6 & $1-4$ & 3.55 & 0.67 & -1.50 & 2.10 \\
\hline P7 & $1-4$ & 3.59 & 0.66 & -1.61 & 2.25 \\
\hline N8 & $1-4$ & 2.29 & 1.16 & 0.28 & -1.39 \\
\hline N9 & $1-4$ & 2.85 & 1.03 & -0.38 & -1.06 \\
\hline N10 & $1-4$ & 2.62 & 1.04 & -0.16 & -1.15 \\
\hline GSE & $10-40$ & 30.30 & 4.82 & -0.37 & 0.22 \\
\hline
\end{tabular}

The measures of skewness and kurtosis were examined to determine if any items needed to be removed due to distribution of responses deviating significantly from a normal distribution curve. Univariate normality coefficients ranged between -1.14 and 0.28 for skewness and between -1.16 and 2.25 for kurtosis, confirming their normal distribution, given that there were no items with levels of skewness $>2.5$ and levels of kurtosis $>3.0$, that should be eliminated (Baron, 2018; Tabachnick \& Fidell, 2019).

Bivariate Pearson correlations were calculated to ensure that all proposed items were related to the overarching construct of RSES (inter-item and item-scale associations). Correlations between items and positive and negative dimensions of self-esteem were also calculated (Table 2). Those items that did not correlate with at least one other item at an $r$ value $\geq 0.30$ were discarded. Results revealed low to large magnitude inter-item linear correlations (between -0.06 and 0.53 ), with the lowest values being associated 
with different (positive versus negative) worded items. Item-scale correlations ranged from 0.42 (for item P2) to 0.13 (for item N9). As expected, the positively worded items were more related to the PSE factor (relevant $r$ values ranged from 0.65 to 0.75 ), while the negatively worded ones showed higher correlation values with the NSE factor (relevant $r$ values ranged from 0.64 to 0.79). PSE and NSE latent variables were slightly correlated $(r=0.23, p<0.01)$, suggesting a weak amount of common variation between these factors.

Table 2

Inter-item and item-scale Pearson's correlations

\begin{tabular}{|c|c|c|c|c|c|c|c|c|c|c|c|c|}
\hline & $\mathrm{P} 2$ & N3 & $\mathrm{P} 4$ & N5 & P6 & P7 & N8 & N9 & N10 & PSE & NSE & GSE \\
\hline \multirow[t]{2}{*}{ P1 } & 0.3 & 0.17 & $0.39^{*}$ & & 0.52 & $0.3^{*}$ & & 0.17 & 0.15 & 0.72 & 0.16 & 0.48 \\
\hline & $1 * *$ & $* *$ & $*$ & 0.08 & $* *$ & $*$ & 0.02 & $* *$ & $* *$ & $* *$ & $* *$ & $* *$ \\
\hline \multirow[t]{2}{*}{$\mathrm{P} 2$} & & 0.15 & $0.25^{*}$ & & 0.35 & 0.36 & - & 0.14 & 0.13 & 0.65 & 0.13 & 0.42 \\
\hline & & $* *$ & & $0.1^{*}$ & $* *$ & $* *$ & 0.06 & $* *$ & $* *$ & $* *$ & $* *$ & $* *$ \\
\hline \multirow[t]{2}{*}{ N3 } & & & $0.16^{*}$ & 0.28 & 0.14 & 0.19 & $0.2 *$ & 0.47 & 0.34 & 0.23 & 0.65 & 0.61 \\
\hline & & & $*$ & $* *$ & $* *$ & $* *$ & $*$ & $* *$ & $* *$ & $* *$ & $* *$ & $* *$ \\
\hline \multirow[t]{2}{*}{$\mathrm{P} 4$} & & & & 0.08 & 0.37 & 0.37 & & 0.15 & 0.14 & $0.7 *$ & 0.17 & 0.48 \\
\hline & & & & & $* *$ & $* *$ & 0.07 & $* *$ & $* *$ & $*$ & $* *$ & $* *$ \\
\hline \multirow[t]{2}{*}{ N5 } & & & & & & $0.1 *$ & 0.39 & 0.42 & 0.33 & 0.12 & $0.7 *$ & 0.59 \\
\hline & & & & & 0.07 & $*$ & $* *$ & $* *$ & $* *$ & $* *$ & $*$ & $* *$ \\
\hline \multirow[t]{2}{*}{ P6 } & & & & & & 0.39 & - & 0.17 & 0.18 & 0.75 & 0.16 & 0.49 \\
\hline & & & & & & $* *$ & 0.01 & $* *$ & $* *$ & $* *$ & $* *$ & $* *$ \\
\hline \multirow[t]{2}{*}{ P7 } & & & & & & & & 0.14 & 0.15 & 0.69 & 0.18 & 0.48 \\
\hline & & & & & & & 0.04 & $* *$ & $* *$ & $* *$ & $* *$ & $* *$ \\
\hline \multirow[t]{2}{*}{ N8 } & & & & & & & & 0.34 & 0.23 & & 0.64 & $0.5^{*}$ \\
\hline & & & & & & & & $* *$ & $* *$ & 0.02 & $* *$ & * \\
\hline \multirow[t]{2}{*}{ N9 } & & & & & & & & & 0.53 & 0.22 & 0.79 & 0.71 \\
\hline & & & & & & & & & $* *$ & $* *$ & $* *$ & $* *$ \\
\hline N1 & & & & & & & & & & 0.22 & 0.69 & 0.64 \\
\hline 0 & & & & & & & & & & $* *$ & $* *$ & $* *$ \\
\hline
\end{tabular}

**. Correlation is significant at the 0.01 level (2-tailed).

*. Correlation is significant at the 0.05 level (2-tailed).

\section{Confirmatory Factor Analysis (CFA)}

Table 3 reports the fit indices and comparative fit indices of the two models of the RSES. Based on these results, Model 1 was rejected as poor approximations of the data as it demonstrated unsatisfactory fit indexes (Tucker-Lewis Index < 0.90). Model 2 was found to have a good fit (i.e., CFA, TLI values $>0.90$ and root mean square error of approximation < 0.08). This model also displayed a considerably lower AIC, BIC and CAIC values than the Model 1, further indicating its statistical superiority (AIC = 237.494, $\mathrm{BIC}=238.388$ and $\mathrm{CAIC}=379.975)$. Considering the aforementioned conclusions that confirm previous literature, two subdimensions structure of RSES is better than the unidimensional. 
Table 3

Comparison of the two Fit Indices for the Estimated Models of the RSES

\begin{tabular}{lllllllllll}
\hline Models & $\chi^{2}$ & $\mathrm{df}$ & $\begin{array}{l}\text { CMIN/ } \\
\mathrm{df}\end{array}$ & CFI & TLI & $\begin{array}{l}\text { RMSE } \\
\text { A }\end{array}$ & SRMR & AIC & BIC & CAIC \\
\hline Model 1 & $\begin{array}{l}185.49 \\
4^{*}\end{array}$ & 29 & 6.369 & 0.882 & 0817 & 0.091 & 0.0900 & 237.49 & 238.38 & 379.975 \\
\hline Model 2 & 46.217 & 32 & 1.444 & 0.989 & 0.985 & 0.026 & 0.0336 & 92.217 & 93.007 & 218.258 \\
\hline
\end{tabular}

Note: $\mathrm{N}=652 ; \chi^{2}=$ chi-square goodness of fit statistic; $d f=$ degrees of freedom; $\mathrm{CMIN} / \mathrm{df}=$ minimum discrepancy per degree of freedom; CFI = Comparative Fit Index; TLI = Tucker-Lewis Index; RMSEA = Root Mean Square Error of Approximation; SRMR = Standardized Root Mean Square Residual; AIC = Akaike Information Criterion; $\mathrm{BIC}=$ Bayesian Information Criterion; CAIC $=$ Consistent AIC; $*$ Indicates $\chi^{2}$ is statistically significant $(\mathrm{p}<.05)$.

Following the models fit, the validity and reliability of the Model 2 was evaluated, since it was identified as the best-fitting. CR was used as measure of internal consistency of the latent variables, where values greater than 0.70 are representative of good reliability (Hair et al., 2010). The first latent variable, which is presented by PSE (Items P1, P2, $\mathrm{P} 4, \mathrm{P} 6$, and $\mathrm{P} 7$ ) had a $\mathrm{CR}=0.77$, and the second latent variable which is presented by NSE (Items N3, N5, N8, N9, and N10) had a CR =0.76.

The convergent validity of the RSES model's factors was examined through Average Variance Extracted (AVE). AVE values should be equal or greater than 0.50 and lower than CR in order to establish convergent validity (Hair et al., 2010). In case of AVE is less than 0.5 but $C R$ is higher than 0.6 , the convergent validity of the construct is still adequate (Fornell \& Larcker, 1981). The latent variable PSE had a square root of AVE 0.41 , while the latent variable NSE had a square root of AVE 0.40 .

\section{DISCUSSION}

The purpose of the current study involved the evaluation of the RSES structure over a sample consisting of a Greek primary school student's population. Evidence from this study provides support that the models with latent factors for both negatively and positively worded items led to better fit than unidimensional model. Additionally, the simple unidimensional factor structure model with uncorrelated errors demonstrated unsatisfactory fit. The findings are consistent with other studies, which used two-factor solution in analyzing the factorial nature of the original RSES (Greenberger et al., 2003; Boduszek et al., 2013).

Composite Reliability was selected to measure the internal consistency and the reliability of the scale. This measure indicates the proportion of total test variance, due to the covariance between the items. In this study, a good reliability index (0.76-0.77) was obtained as its value was greater than 0.70 , which is considered acceptable (Hair et al., 2010). This result is consistent with previous studies (Pullmann \& Allik, 2000; Boduszek et al., 2013).

Thus, the two-factor structure of RSES is considered appropriate for children, but future researchers should be aware that the results might be affected by the difficulties which young students can face in responding appropriately to negatively worded items as per 
Marsh research (1986; cited in Marsh, 1996) over a sample of preadolescent students. Besides, an additional research by Corwyn (2000) highlights the fact that negatively worded items may confuse children and adolescents with relatively lower capability of expressing ideas using words in a clearly understandable manner, thus leading to systematic errors.

As the current study did not directly consider some critical factors of method bias, such as verbal ability of the students, a more comprehensive study is required to verify the aforementioned remarks and findings, as well as demonstrate any alternative approaches. Finally, the implementation of more advanced statistical tools might also assist in the identification of the method bias effect more efficiently.

\section{CONCLUSION}

In conclusion, the key contribution of this study is the adaptation and evaluation of the RSES for use of Greek students and the determination of its factor structure. The RSES was found to assess two factor constructs and not the one-dimensional construct of global self-esteem that was originally conceived by Rosenberg (1965). Teachers and researchers could also use this interpreted scale to determine the level of self-esteem in primary school children and create strategies to increase their self-esteem.

\section{ACKNOWLEDGEMENTS}

This research is co-financed by Greece and the European Union (European Social FundESF) through the Operational Programme «Human Resources Development, Education and Lifelong Learning» in the context of the project "Strengthening Human Resources Research Potential via Doctorate Research" (MIS-5000432), implemented by the State Scholarships Foundation (IKY).

\section{REFERENCES}

Alsalkhi, M. (2018). Satisfaction of Academic Specialization among Students of the Department of Educational Sciences and Its Relation to Self-Esteem. International Journal of Instruction, 11(4), 107-122.

Baron, C. (2018). Surveys and scales in EDI research. In L. A. E. Booysen, R. Bendl, \& J. K. Pringle (Eds.), Handbook of research methods on diversity management, equality and inclusion at work. Northampton, MA: Edward Elgar Publishing.

Batsiou, S., Bournoudi, S., Antoniou, P., \& Tokmakidis, S. P. (2020). Self-Perception Self-Esteem Physical Activity and Sedentary Behavior of Primary Greek- School Students: A Pilot Study. International Journal of Instruction, 13(1), 267-278.

Baumeister, R. F. (Ed.). (1993). Self-esteem: The puzzle of low self-regard. New York: Plenum Press.

Boduszek, D., Hyland, P., Dhingra, K., \& Mallett, J. (2013). The factor structure and composite reliability of the Rosenberg Self-Esteem Scale among exprisoners. Personality and Individual Differences, 55, 877-881.

Bollen, K. A., \& Long, J. S. (1993). Testing structural equation models. Newbury Park: Sage Publications. 
Branden, N. (1994). The six pillars of self-esteem. New York: Bantam Books.

Browne M. W., \& Cudeck R. (1992). Alternative ways of assessing model fit. Sociological Methods \& Research, 21, 230-258. doi: 10.1177/0049124192021002005

Byrne, B. M. (1996). Measuring self-concept across the lifespan: Issues and instrumentation. Washington, DC: American Psychological Association.

Cole, M. \& Cole, S. (2001). The development of children. Athens: Gutenberg.

Corwyn, R. F. (2000). The factor structure of global self-esteem among adolescents and adults. Journal of Research in Personality, 34, 357-379.

DiStefano, C., \& Motl, R. W. (2009). Personality correlates of method effects due to negatively worded items on the Rosenberg Self-Esteem Scale. Personality and Individual Differences, 46, 309-313. doi:10.1016/j.paid.2008.10.020

Fornell, C., \& Larcker, D. F. (1981). Evaluating structural equation models with unobservable variables and measurement error. Journal of Marketing Research, 18(1), 39-50. doi:0.2307/3151312

Galanou, C.; Galanakis, M.; Alexopoulos, E., \& Darviri, C. (2014). Rosenberg Self Esteem Scale--Greek Version (RSES), Psychology, 5, 819-827. Doi: 10.4236/psych.2014.58093

Greenberger, E.; Chen, C.; Dmitrieva, J., \& Farruggia, S. P. (2003). Itemwording and the dimensionality of the Rosenberg Self-Esteem Scale: Do they matter? Personality and Individual Differences, 35, 1241- 1254.

Hair, J.; Black, W.; Babin, B., \& Anderson, R. (2010). Multivariate data analysis (7th ed.). Upper Saddle River, NJ: Prentice-Hall.

Hooper, D.; Coughlan, J., \& Mullen, M. (2008). Structural equation modelling: Guidelines for determining model fit. Electronic Journal of Business Research Methods, 6(1), 53-60.

Hu, L.-t., \& Bentler, P. M. (1999). Cutoff criteria for fit indexes in covariance structure analysis: Conventional criteria versus new alternatives. Structural Equation Modeling, 6(1), 1-55. Doi:10.1080/10705519909540118

Jacobs, J. E.; Bleeker, M. M., \& Constantino, M. J. (2003). The self-system during childhood and adolescence: Development, influences, and implications. Journal of Psychotherapy Integration, 13(1), 33-65. doi:10.1037/1053-0479.13.1.33

Joiner, T. E. Jr. (1995). The price of soliciting and receiving negative feedback: Selfverification theory as a vulnerability to depression theory. Journal of Abnormal Psychology, 104, 364-372.

Kaufman, P.; Rasinski, K. A.; Lee, R., \& West, J. (1991). National Education Longitudinal Study of 1988. Quality of the responses of eighth-grade students in NELS88. Washington, DC: U.S. Department of Education.

Kobal, D. \& Musek, J. (2001). Self-concept and academic achievement: Slovenia and France. Personality and individual differences, 30(5), 887-899. 
Marsh, H. W. (1996). Positive and negative global self-esteem: A substantively meaningful distinction or artifactors? Journal of Personality and Social Psychology, 70(4), 810-819.

Michaelides, M. P.; Koutsogiorgi, C., \& Panayiotou, G. (2015). Method Effects on an Adaptation of the Rosenberg Self-Esteem Scale in Greek and the Role of Personality Traits. Journal of Personality Assessment, 98(2), 178188. doi:10.1080/00223891.2015.1089248

Miller, D.; Topping, K., \& Thurston, A. (2010). Peer tutoring in reading: The effects of role and organization on two dimensions of self-esteem. British Journal of Educational Psychology, 80(3), 417-433. doi:10.1348/000709909x481652

Nunnally, J. C. (1978). Psychometric Theory (2nd ed.). New York McGraw-Hill.

Penninx, B. W. J. H.; van Tilburg, T.; Boeke, J. P.; Deeg, D. J. H.; Kriegsman, D. M. W., \& van Eijk, J. T. M. (1998). Effects of social support and personal coping resources on depressive symptoms: Different for various chronic diseases? Health Psychology, 17, 551-558.

Pullmann, H., \& Allik, J. (2000). The Rosenberg Self-Esteem Scale: its dimensionality, stability and personality correlates in Estonian. Personality and Individual Differences, 28, 701-715.

Ralph, J. A., \& Mineka, S. (1998). Attributional style and self-esteem: The prediction of emotional distress following a midterm exam. Journal of Abnormal Psychology, 107, 203-215.

Rosenberg, M. (1965). Society and the adolescent child. Princeton, NJ: Princeton University Press.

Rosenberg, M. (1979). Conceiving the self. New York: Basic Books.

Schacter, D. L.; Gilbert, D. T., \& Wegner, D. M. (2012). Psychology. Athens: Gutenberg.

Silver, E. J.; Bauman, L. J., \& Ireys, H. T. (1995). Relationships of self-esteem and efficacy to psychological distress in mothers of children with chronic physical illnesses. Health Psychology, 14, 333-340.

Tabachnick, B. G., \& Fidell, L. S. (2019). Using multivariate statistics (7th ed.). Boston, MA: Pearson.

Tomás, J., Sancho, P., Galiana, L., Oliver, A., \& Hontangas, P.M. (2016). Measuring self-esteem in Spanish adolescents: Equivalence across gender and educational levels. Avaliaçao Psicologica: Interamerican Journal of Psychological Assessment, 14, 385-393.

Whiteside-Mansell, L., \& Corwyn, R. F. (2003). Mean and covariance structures analyses: An examination of the Rosenberg Self-Esteem Scale among adolescents and adults. Educational and Psychological Measurement, 63, 163-173. 